\title{
An APETALA1 ortholog affects plant architecture and seed yield component in oilseed rape (Brassica napus L.)
}

\author{
Smit Shah, Nirosha L. Karunarathna, Christian Jung and Nazgol Emrani* (i)
}

\begin{abstract}
Background: Increasing the productivity of rapeseed as one of the widely cultivated oil crops in the world is of upmost importance. As flowering time and plant architecture play a key role in the regulation of rapeseed yield, understanding the genetic mechanism underlying these traits can boost the rapeseed breeding. Meristem identity genes are known to have pleiotropic effects on plant architecture and seed yield in various crops. To understand the function of one of the meristem identity genes, APETALA1 (AP1) in rapeseed, we performed phenotypic analysis of TILLING mutants under greenhouse conditions. Three stop codon mutant families carrying a mutation in Bna. AP1.A02 paralog were analyzed for different plant architecture and seed yield-related traits.

Results: It was evident that stop codon mutation in the K domain of Bna.AP1.A02 paralog caused significant changes in flower morphology as well as plant architecture related traits like plant height, branch height, and branch number. Furthermore, yield-related traits like seed yield per plant and number of seeds per plants were also significantly altered in the same mutant family. Apart from phenotypic changes, stop codon mutation in $\mathrm{K}$ domain of Bna.AP1.A02 paralog also altered the expression of putative downstream target genes like Bna.TFL1 and Bna.FUL in shoot apical meristem (SAM) of rapeseed. Mutant plants carrying stop codon mutations in the $\mathrm{COOH}$ domain of Bna.AP1.A02 paralog did not have a significant effect on plant architecture, yield-related traits or the expression of the downstream targets.

Conclusions: We found that Bna.AP1.A02 paralog has pleiotropic effect on plant architecture and yield-related traits in rapeseed. The allele we found in the current study with a beneficial effect on seed yield can be incorporated into rapeseed breeding pool to develop new varieties.
\end{abstract}

Keywords: Meristem identity genes, TILLING, EMS-induced mutations, Plant height, Branch height, Seed yield

\section{Background}

Rapeseed (Brassica napus L., AACC, $2 \mathrm{n}=38$ ) is one of the most important oil crops in the world for the production of vegetable oil and animal feed. The productivity of rapeseed has been significantly increased in the last ten years, mainly due to the high yielding cultivars, mechanical harvesting, and better agronomic practices. Nevertheless, to meet the increasing demand for edible oil worldwide, it is important to understand the genetic mechanism underlying rapeseed productivity [1]. To increase the

* Correspondence: n.emrani@plantbreeding.uni-kiel.de

Plant Breeding Institute, Christian-Albrechts-University of Kiel, Olshausenstr. 40, 24098 Kiel, Germany productivity, optimization of flowering time and plant architecture is fundamental.

Flowering time plays a very crucial role in the environmental adaptation of the plant. Environmental adaptation mainly includes the adaptation to prevailing climatic conditions (for example season, day length, and temperature), as well as biotic and abiotic stresses. The adaptation to the environment is important for the overall yield of the plant. It is known from the model plant Arabidopsis that environmental factors like cold temperature, photoperiod, and ambient temperature, as well as, genetic and epigenetic factors, influence floral transition. Under long day conditions, the floral inducers CONSTANS (CO) and FLOWERING LOCUS $T(F T)$ are activated and trigger the expression of meristem identity genes like $L E A F Y(L F Y)$,

(c) The Author(s). 2018 Open Access This article is distributed under the terms of the Creative Commons Attribution 4.0 International License (http://creativecommons.org/licenses/by/4.0/), which permits unrestricted use, distribution, and 
APETALA1 (AP1), SEPALLATA3 (SEP3) and FRUITFULL $(F U L)$. Subsequently, meristem identity genes transform the Arabidopsis shoot apical meristem into a floral meristem [2]. In contrast to FT, TERMINAL FLOWER-1 (TFL1), which shares high sequence similarity (71\%) with $F T$, represses downstream meristem identity genes such as $A P 1$ and $L F Y$ in the central zone of the meristem. Considering the close phylogenetic relationship between rapeseed and Arabidopsis, knowledge of flowering time control in Arabidopsis provides the basis to understand the regulatory network in rapeseed. However, knowledge transfer from Arabidopsis to rapeseed is hindered by the complexity of the rapeseed genome. Different approaches have been applied to unveil the flowering time mechanism in rapeseed. Application of bi-parental populations for mapping quantitative trait loci (QTL) for flowering time and other agronomic traits is one of the widely used approaches [3-5]. In one of such studies, Raman et al. [6] mapped 20 different flowering time loci to 10 different chromosomes using a doubled haploid (DH) population, derived from a cross between two vernalization responsive rapeseed cultivars. They reported that three paralogs of Bna.AP1 coincided with flowering time QTL on chromosomes A02, A07, and A08. Nevertheless, up to now no studies in rapeseed have demonstrated the phenotypic effect of Bna.AP1 overexpression or mutation on flowering time.

In addition to flowering time, selecting plants with ideal architecture is also crucial for crop domestication and improvement [7]. Therefore, over the years, there have been several studies in major crops to understand the mechanisms, which control plant architecture. For example, in rice, the ideal plant architecture (IPA) plant was reported to have thicker and more robust stems with more grains per panicle [7]. Variation in the leaf angle also showed a significant effect on maize grain yield, underpinning the importance of plant architecture in optimizing crop yield [8, 9]. Plant height, branch length, branch angle, length of main inflorescences, leaf angle and branch number per plant define plant architecture in $B$. napus, which affect seed yield components like silique number per plant and also number of seeds per plant [10, 11]. Cai et al. [1] mapped 163 QTL related to plant architecture and yield-related traits in a $\mathrm{DH}$ population comprising 254 individuals. In another study, Shen et al. [12] could identify 19 QTL related to plant height, branch initiation height, stem diameter and flowering time in a DH population with 208 individuals. Using the same population, 17 QTL for branch angle were found, of which, three major QTL were steadily expressed, each explaining more than $10 \%$ of the phenotypic variation [13]. Besides genetic mapping, association mapping has also been used to find candidate genes for the trait of interest. In one of such GWAS studies [14],
158 winter rapeseed accessions were phenotyped for flowering time, plant height and seed yield in 11 different environments across Germany, China and Chile. These accessions were genotyped using the Brassica 60 K-SNP Illumina ${ }^{\circ}$ Infinium consortium array. They found 68 regions across the rapeseed genome, which showed multi-trait associations. Using the same SNP array, Li et al. [15] genotyped 472 diverse rapeseed accessions to find regions associated with rapeseed branch angle. They found 21 loci across the genome with significant associations with branch angle. In another GWAS study, Zheng et al. [16] genotyped and phenotyped 333 rapeseed accessions across 4 years and found seven loci for plant height, four for branch initiation height, and five for branch number.

During plant development, the shoot apical meristem (SAM) transforms into an inflorescence meristem and finally into a floral meristem. Subsequently, sepals, petals, stamen, and carpel of the flower are developed from the floral meristem. Several meristem identity genes play an important role in the development of floral organs. Moreover, there are reports in crops suggesting the role of meristem identity genes in controlling plant architecture [17-19]. Meristem identity and determinacy are controlled by the overlapping expression of meristem identity genes of the ABCE model [20]. In Arabidopsis, A-functional genes include APETALA1(AP1) and APETALA2(AP2), B- functional genes include APETALA3 (AP3) and PISTILLATA (PI), C- functional genes include AGAMOUS (AG), and Efunctional genes include SEPALLATA orthologs (SEP1$S E P 4)$ [21]. AP1 plays a crucial role in floral meristem identity and also in sepal and petal development in Arabidopsis [22]. In Arabidopsis, a mutation in AP1 causes the conversion of sepals into bracts as well as the development of floral buds in the axil of transformed sepals. Moreover, the flowers of the mutant plants also lack petals [23]. Previous studies demonstrated the ability of APlorthologs from various plant species (Jatropha curcas [24], Orange [25], Pea [26] and Lily [27]) to complement Arabidopsis ap1 phenotype, which indicates the conservation of the role of $A P 1$ between different species. However, orthologs of AP1 have not been yet functionally characterized in rapeseed.

In the current study, we aimed to characterize the function of an AP1 ortholog in rapeseed using TILLING (Targeting Induced Local Lesions in Genomes). Based on our phenotypic evaluation, we report that a stop codon mutation in Bna.AP1.A02 alters plant architecture in rapeseed and increases the number of seeds per plant. Moreover, we found that a stop codon mutation in Bna.AP1.A02 also leads to modifications in floral architecture similar to an Arabidopsis AP1 mutant phenotype. Our data suggest that EMS-generated alleles can be useful to develop high yielding varieties by conventional breeding and can also be valuable to increase genetic diversity for rapeseed breeding. 


\section{Methods}

\section{Mutation screening}

We screened $3840 \mathrm{M}_{2}$ plants of the EMS Express617 winter rapeseed mutant population [28] by TILLING. For TILLING, we used normalized DNA $(5 \mathrm{ng} / \mu \mathrm{l})$ from $\mathrm{M}_{2}$ plants which was arranged into ten 96-well microtiter plates using two-dimensional (2D) eight-fold (8x) pooling strategy [28]. We designed paralog-specific primers for Bna.AP1.A02 and Bna.AP1.C02 (Additional file 1: Table S1) using the published reference genome sequence [29]. Subsequently, we performed CelI digestion of heteroduplexes, sample purification and polyacrylamide gel electrophoresis (PAGE) on a LI-COR 4300 DNA analyzer (LI-COR Biosciences, http://www.licor.com) according to Harloff et al. [28]. We used GelBuddy Software [30] to identify mutations.

\section{Plant material and growth conditions}

$\mathrm{M}_{4}$ seeds were produced by selfing of $\mathrm{M}_{3}$ plants of three Bna.AP1.A02 stop codon mutant families. From each family, $20 \mathrm{M}_{4}$ seeds per genotype (mutant and wildtype) together with Express617 were sown in the greenhouse for phenotyping. All plants were grown in the greenhouse under constant temperature $\left(22^{\circ} \mathrm{C}\right)$ and long day conditions $\left(16 \mathrm{~h}\right.$ light, $900 \mu \mathrm{mol} \mathrm{m}^{-2} \mathrm{~s}^{-1}$, Son-T Agro 400 W, Koninklijke Philips Electronics N.V., Eindhoven, Netherlands). After three weeks of pre-culture, we transferred the plants to a cold chamber at $4{ }^{\circ} \mathrm{C}$ (vernalization) under long day conditions (16 h light, $200 \mu \mathrm{mol} \mathrm{m}-2 \mathrm{~s}-1$, Osram Lumilux T8 L $58 \mathrm{~W} / 840$, Osram AG, München, Germany) for eight weeks. After vernalization, we transferred the plants to the initial greenhouse conditions and transplanted them into $11 \times$ $11 \mathrm{~cm}$ pots. We randomized the plants two times a week.

\section{Plant phenotyping and statistical analysis}

We measured the total number of seeds per plant, seed yield per plant (g) and a total number of healthy and filled siliques per plant. Moreover, we measured plant height (length of the plant from the base of stem to the top of the main inflorescence at maturity), branch height (distance from the base of the stem to the first branch [1]) and branch number (the total number of primary and secondary branches at maturity). For all the phenotypic traits, we took an average of 15 plants of each, mutant (aa), wildtype $(A A)$ and Express617. The mean comparison between the genotypes for the investigated traits was performed by ANOVA (Analysis of variance) test ( $P$ value $=0.0001)$, while the grouping was done using the LSD test $(\alpha \leq 0.05)$. For LSD test, we used the R package 'Agricolae' version 1.2-8.

\section{Gene expression analysis}

We collected SAM tissue from three $M_{4}$ vernalized plants (BBCH 30) [31] at Zeitgeber time (ZT) 8. We performed RNA isolation from three biological replicates with the peqGold Plant RNA Kit (PEQLAB Biotechnologie $\mathrm{GmbH}$, Erlangen, Germany) according to the manufacturer's protocol. RNA concentration and purity was determined by agarose gel electrophoresis and photometric quantification with a NanoDrop spectrophotometer (Thermo Scientific). We treated total RNA with DNAse I (Fermentas Inc., Maryland, USA) to remove genomic DNA. Subsequently, we synthesized the first-strand cDNA from $1 \mu \mathrm{g}$ of DNA-depleted RNA using Oligo (dT)18 primers and the M-MuLV Reverse Transcriptase (ThermoFisher Scientific, Waltham, United States). For quality check, a standard PCR of the synthesized cDNAs (1,10 dilution) was performed with the housekeeping gene Bna.Actin (rapeseed actin gene, GenBank Accession No. AF111812). Prior to expression analysis, we developed primers for Bna.TFL, Bna.LFY, Bna.SEP4, Bna.FUL and Bna.AP1 (Additional file 1: Table S1). Moreover, we designed paralog-specific primers for Bna.TFL paralogs (Bna.TFL1.A10, Bna.TFL1.C3 and Bna.TFL1.Ann) and the amplicons were Sanger sequenced.

We performed quantitative real-time RT-PCR (RT-qPCR) with SYBR qPCR Super mix w/ROX (Invitrogen Corporation, Carlsbad, USA) using a CFX96 Real-Time System (Bio-Rad Laboratories GmbH, München, Germany). For each reaction, we used a total volume of $20 \mu \mathrm{l}$ containing $100 \mathrm{nM}$ of each primer and $2 \mu \mathrm{l}$ of diluted cDNA templates with the following cycling conditions: $95^{\circ} \mathrm{C}$ for $3 \mathrm{~min}, 40$ cycles of $95^{\circ} \mathrm{C}$ for $10 \mathrm{~s}, 60^{\circ} \mathrm{C}$ for $30 \mathrm{~s}$, and $72{ }^{\circ} \mathrm{C}$ for $30 \mathrm{~s}$, followed by $95^{\circ} \mathrm{C}$ for $10 \mathrm{~min}$. Primer efficiencies for the different targets were determined using four 2-fold serial dilutions of cDNA and were included in the calculation of relative expression levels in Bio-Rad CFX Manager 3.1. We analyzed the amplification curves and used the average $\mathrm{Ct}$ values of three technical replicates to calculate relative expression in comparison to the reference gene (Bna.Actin) using the $\Delta \Delta \mathrm{Ct}$ method [32].

\section{Results}

Identification of Bna.AP1 stop codon mutants by TILLING We performed amino acid sequence alignments between A. thaliana (AtAP1) and six rapeseed (Bna.AP1) AP1 proteins to identify the conserved regions. Based on protein alignments, amino acid sequences are highly conserved between Arabidopsis and rapeseed proteins (Fig. 1). We concluded that all four functional domains present in AtAP1 (MADS domain, I domain, K domain, and $\mathrm{COOH}$ domain) are also present in five out of six predicted Bna.AP1 proteins. Only, Bna.AP1.C02 lacks a MADS-box domain based on the published rapeseed genome sequence [29]. We selected two paralogs, 


\begin{tabular}{|c|c|c|c|c|c|c|c|c|c|c|}
\hline \multicolumn{3}{|c|}{ N-terminal } & \multicolumn{8}{|c|}{ MADS domain } \\
\hline & & & 7 & $\frac{40}{1}$ & & & & & & \\
\hline AtAP1 & & & -MGRGRVQLK & RIENK INRQV & TFSKRRAGLL & KKAHE I SVLC & DAEVALVVFS & HKGKLFEYST & DSCMEK I LER 6 & \\
\hline Bna.AP1.C06a & MQSEGDTWDG & PVEIVPLKGI & KMGRGRVQLK & RIENKINRQV & TFSKRRAGLM & KKAHE I SVLC & DAEVALVVFS & HKGKLFEYST & DSCMEKI LER & \\
\hline Bna.AP1.A07a & MQSGGDTWDG & PVEIVPLKGI & KMGRGRVQLK & RIENK INRQV & TFSKRRAGLM & KKAHE I SVLC & DAEVALVVFS & HKGKLFEYST & DSCMEKILER & \\
\hline Bna.AP1.C06b & & 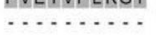 & -MGRGRVQLK & RIENKINRQV & TFSKRRAGLF & KKAHE I SVLC & DAEVALVVFS & HKGKLFEYST & DSCMEKILER & \\
\hline Bna.AP1.A07b & . & $\cdots$ & -MGRGRVQLK & RIENKINRQV & TFSKRRAGLF & KKAHE I SVLC & DAEVALVVFS & HKGKLFEYST & DSCMEKI LER 6 & \\
\hline \multirow{4}{*}{$\begin{array}{l}\text { Bna.AP1.A02 } \\
\text { Bna.AP1.C02 }\end{array}$} & n. & - $\ldots \ldots \ldots$, & -MGRGRVQLK & RIENK INRQV & TFSKRRAGLL & KKAHE I SVLC & DAEVALVVFS & HKGKLFEYST & DSCMEKILER 6 & \\
\hline & n....... & $\ldots \ldots$ & $\ldots$ & $\ldots$ & $\ldots \ldots$ & $\ldots \ldots$ & $\ldots \ldots$ & $\ldots \ldots$ & ..MEKILER & \\
\hline & ld dom & main & $* * * * * * * * *$ & $* * * * * * * * * *$ & $* * * * * * * * *$ & $\begin{array}{c}* * * * * * * * * * \\
\mathrm{~K} \text { domain }\end{array}$ & $* * * * * * * * * * *$ & $* * * * * * * * * *$ & $* * * * * * * * * *$ & \\
\hline & $\begin{array}{l}100 \\
1\end{array}$ & & 120 & & $\begin{array}{l}140 \\
1\end{array}$ & & 166 & & & \\
\hline AtAP1 & YERYSYAERQ & LIAPESDVNT & NWSMEYNRLK & AKIELLERNQ & RHYLGEDLQA & MSPKELQNLE & QQLDTALKHI & RTRKNQLMYE & SINELQKKKEK & 159 \\
\hline Bna.AP1. C06a & YERYSYAERQ & $\begin{array}{l}\text { LIAPESDSNT } \\
\text { LIPST }\end{array}$ & NWSMEYNRLK & $\begin{array}{l}\text { AKIELLERNQ } \\
\text { AKIERN }\end{array}$ & RHYLGEDLQA & MSPKELQNLE & QQLDTALKHI & RSRKNQLMYD & S INELQRKEK & 180 \\
\hline Bna.AP1.A07a & YERYSYAERQ & LIAPESDSNT & NWSMEYNRLK & AKIELLERNQ & RHYLGEDLQA & MSSKELQNLE & QQLDTALKHI & RSRKNQLMYD & S INELQRKEK & 180 \\
\hline Bna.AP1. C06b & YERYSYAERQ & LIAPESDVNT & NWSMEYNRLK & AK IELLERNQ & RHYLGEDLQA & MSPKELQNLE & QQLDTALKHI & RSRKNQLMYD & SVINELQRKEK & 159 \\
\hline Bna.AP1.A07b & YERYSYAERQ & LI SPESDVNT & NWSMEYNRLK & AKIELLERNQ & RHYLGEDLQA & MSPKELQNLE & QQLDTALKHI & RSRKNQLMYD & SVNELQRKEK & 159 \\
\hline \multirow{5}{*}{$\begin{array}{l}\text { Bna.AP1.AU2 } \\
\text { Bna.AP1.C02 }\end{array}$} & YERYSYAERQ & LIAPESDVNT & NWSMEYNRLK & AKI DLLERNQ & RHYLGEDLQA & MSSKELQNLE & QQLDTALKHI & RSRKNQLMYD & S I NELQRKEK & 159 \\
\hline & YERYSYAERQ & LIAPESDVNT & NWSMEYNRLK & AKIDLLERNQ & RHYLGEDLQA & MSSKELQNLE & QQLDTALKHI & RSRKNQLMYD & S I NELQRKEK & 97 \\
\hline & $* * * * * * * * * *$ & $* * \cdot * * * * \cdot * *$ & $* * * k * * k * * * *$ & $* * *, * * * * * *$ & $k * * * * * * * * * * *$ & $* *, * * * * * * *$ & $* * * * * * * * * *$ & $*, * * * * * * *$ & $*, * * * *, * * *$ & \\
\hline & \multicolumn{10}{|c|}{$\mathrm{COOH}$ domain } \\
\hline & \multicolumn{2}{|r|}{200} & & 220 & & 240 & & 260 & & \\
\hline AtAP1 & AIQEQNSMLS & KQIKEREKIL & RAQQEQWDQQ & NQGHNMPPPL & PPQQHQIQHP & YMLSHQPSPF & LNMG - & ...GLYQ & EDDDPMAMRRN & 237 \\
\hline Bna.AP1.C06a & A IQEQNSMLS & KQIKERENVL & RAQQEQWDEQ & NHGHNMPPPP & PPQQHQIQHP & YML SHQPSPF & LNMG - . & $\ldots G L Y Q$ & EEDQMAMRRN & 258 \\
\hline Bna.AP1.A07a & A IQEQNSMLS & KQIKEREKVL & RAQQEQWDEQ & NHGHNMPPPP & PPQQHQIQHP & YMLSHQPSPF & LNMGYTYVDN & FVSYIMGLYQ & EEDQMTMRRN & 270 \\
\hline Bna.AP1.C06b & A IQEQNSMLS & KQIKEREKVL & MAQQEQWDQQ & NHGQNMP SPP & PPQQHQIQHP & YMLSHQPSPF & LNMG ....... & $\ldots . . . G L Y Q$ & EEDPMAMRRN & 237 \\
\hline Bna.AP1.A07b & AIQEQNSMLS & KQIKEREKVL & RAQQEQWDQQ & NHGQNMPPPP & PPQEHQIQHP & YMLSHQPSPF & LNMG...... & ......GLYE & EEDPMAMRRN & 237 \\
\hline \multirow{4}{*}{$\begin{array}{l}\text { Bna.AP1.AOL } \\
\text { Bna.COA }\end{array}$} & AIHEQNSMLS & KEIKEREKIL & RAQQEQWDQQ & NHGHNVPPPP & PPQQHQIQHP & YMLSHQPSPF & LNMG ...... & $\ldots \ldots$ GLYQ & EEDSMAMRRN & 237 \\
\hline & AIQEQNSMLS & KEIKEREKIL & RVQQEQWDQQ & NHGHNMPPPP & PPQQHQIQHP & YMLSHQPSPF & LNMG...... & $\ldots . . . G L Y Q$ & EEDSMAMRSN & 175 \\
\hline & $* * * * * * * * * * *$ & $* \cdot * * * * * \cdots *$ & $\ldots * * * * * * \cdot *$ & $* \cdot * \cdot * \cdot * \cdot *$. & $* * *, * * * * * *$ & $* * * * * * * * * *$ & $* * * * \ldots \ldots$ & $\ldots \ldots * * *$ & $*, *, *, * *, *$ & \\
\hline & 280 & 2 & & & & & & & & \\
\hline AtAP1 & DLELTLEPVY & NCNLGCFAA - & & & & & & & & \\
\hline Bna.AP1.C06a & DLDLSLEPVY & NCNLGCFAA & & & & & & & & \\
\hline Bna.AP1.A07a & DLDLSLEPVY & NCNLGCFAA * & 290 & & & & & & & \\
\hline Bna.AP1.C06b & DLDLSLEPVY & NCNLGCFAA : & 257 & & & & & & & \\
\hline Bna.AP1.A07b & DLDLSLEPVY & NCNLGCFAS * & & & & & & & & \\
\hline \multirow{3}{*}{$\begin{array}{l}\text { Bna.AP1.A02 } \\
\text { Bna.AP1.C02 }\end{array}$} & DLDLSLEPVY & NCNLGCFAS * & & & & & & & & \\
\hline & DLDLSLEPVY & NCNLGCFAS: & 195 & & & & & & & \\
\hline & $* * \cdot * \cdot * * * * *$ & & & & & & & & & \\
\hline 19 & acid alignment b & 1 & 的1 & 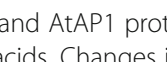 & 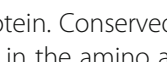 & 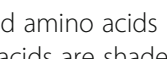 & 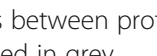 & in & ated bu at & \\
\hline
\end{tabular}

Bna.AP1.A02 and Bna.AP1.C02 for mutation screening, to study the function of $A P 1$ orthologs in rapeseed. These two paralogs were selected based on leaf transcriptome analysis data of semi-winter rapeseed cultivar "Ningyou7" [33], expressed sequence tags (EST) data available for winter rapeseed cultivar 'Darmor-bzh' in the genome database [29] and the study of genetic variation in Bna.AP1 paralogs between different $B$. napus morphotypes [34]. Moreover, according to preliminary data from a transcriptome study in shoot apical meristem of rapeseed, Bna.AP1.A02 and Bna.AP1.C02 showed higher expression compared to the other four paralogs (Siegbert Melzer, Personal communication). We designed paralog-specific primers and the Bna.AP1.A02 and Bna.AP1.CO2 amplicons covered 88.7 and $55.9 \%$ of the coding sequences, respectively. We screened 3488 $\mathrm{M}_{2}$ plants for Bna.AP1.A02 and $2720 \mathrm{M}_{2}$ plants for Bna.AP1.C02 paralog to find mutations. After confirmation by sequencing, we found 164 mutations in the Bna.AP1.A02 paralog and 32 mutations in the Bna.AP1.C02 paralog (Additional file 2: Table S2). For Bna.AP1.A02, we identified six premature stop codon mutations (nonsense) in exon 4, exon 7 and exon 8. Moreover, we also found one splice site mutation in Bna.AP1.C02 at the 5'end of intron 4 (Fig. 2). We considered three premature stop codon mutants of Bna.AP1.A02 (annotated as ap1_1, ap1_2, and ap1_3) for further phenotyping in the greenhouse (Additional file 3: Table S3). We selected these three mutants, because the premature stop codon for each of the selected mutant families was on a different exon, resulting in truncated proteins of different lengths. The splice site mutant found in Bna.AP1.C02 copy was not considered for phenotyping along with three stop codon mutant families, because in an earlier greenhouse experiment, no phenotypic difference was observed between Bna.AP1.C02 splice site mutant plants and the controls (data not shown).

\section{Effect of Bna.AP1.A02 on flowering time, plant architecture and seed yield components}

We recorded flowering time, plant height, branch height, number of seeds/plant, seed yield/plant, siliques/plant and branch number/plant of $15 \mathrm{M}_{4}$ plants per genotype for three stop codon mutant families, to investigate the effect of the mutations in Bna.AP1.A02. For ease of understanding, the mutant allele was termed ' $a$ ' and the wildtype allele was termed as ' $A$.' All three families 


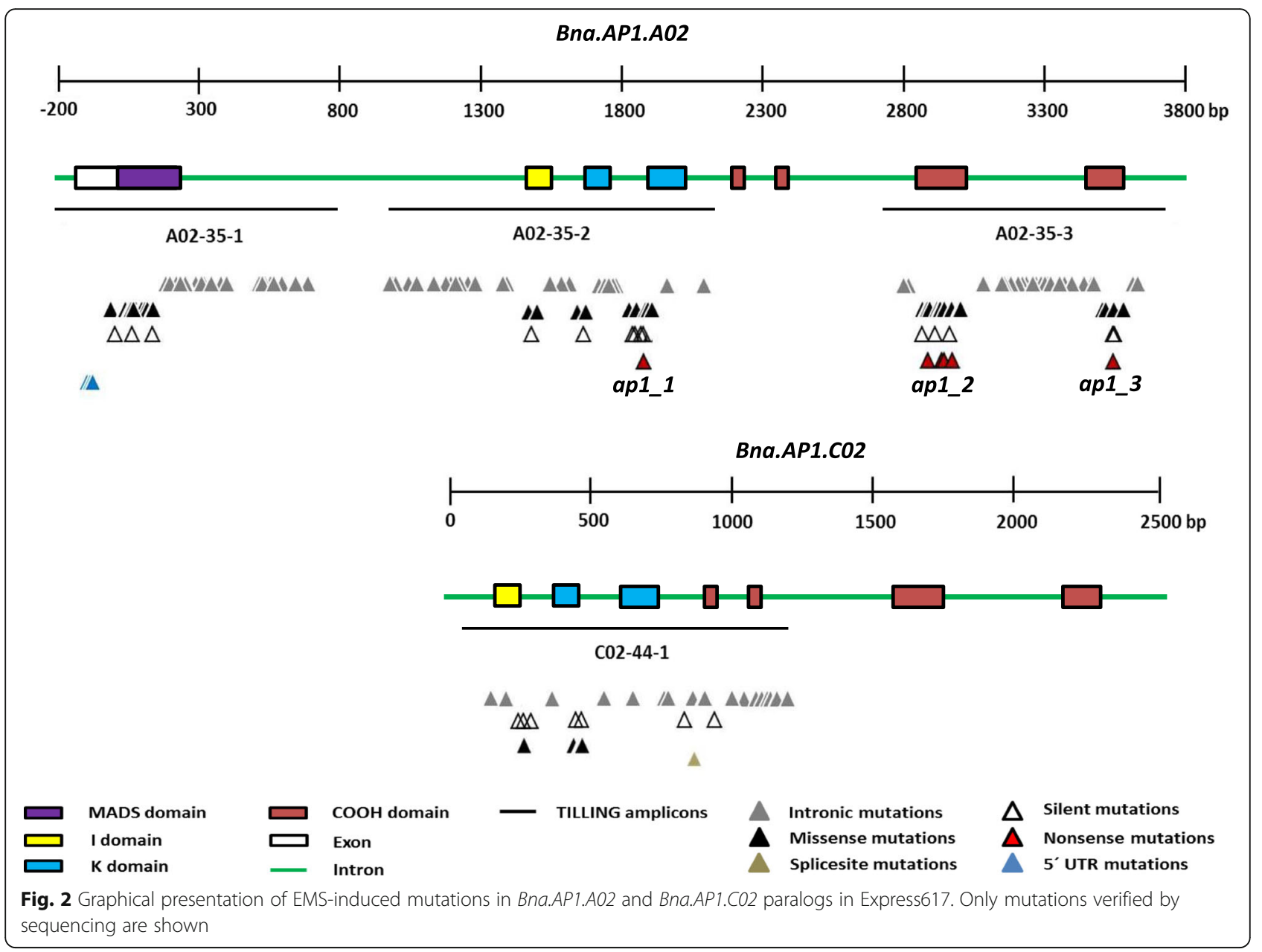

consisted of mutant $(a a)$ and wildtype $(A A)$ genotypes, which were obtained by selfing of the $\mathrm{M}_{3}$ plants (Additional file 3: Table S3). In this context, a wildtype $(A A)$ genotype was generated from the same mutant family and hence, it is expected to have all background mutations as they are in the mutant genotype $(a a)$, except at the loci of interest (Bna.AP1.A02). Therefore, within each mutant family, we compared the mutant $(a a)$ with the wildtype genotype $(A A)$. For all the phenotypic traits, the comparison between the mutant $(a a)$ and the wildtype genotype $(A A)$ was the most important one since they had the same background mutations. This suggests that all the phenotypic variations observed between the mutant $(a a)$ and the wildtype genotype $(A A)$ plants were due to the stop codon mutation in Bna.AP1.A02. We used Express617 as a non-mutated control. We observed that there was no significant difference in the flowering time between mutant and wildtype plants for all three families (data not shown).

The homozygous ap1_1 mutant plants (aa) displayed secondary flower buds instead of sepals, which later developed into siliques (Fig. 3). The same mutant family also exhibited modified plant architecture-related traits like plant height, branch height, and branch number compared to the wildtype plants $(A A)$ of the same family (Fig. 4). We observed that plant height and branch height was increased in the mutant plants $(116.9 \pm 5 \mathrm{~cm}$ and 43.0 $\pm 10.66 \mathrm{~cm}$, respectively) compared to the wildtype plants $(109.3 \pm 6.3 \mathrm{~cm}$ and $31.0 \pm 6.8 \mathrm{~cm}$, respectively). Moreover, ap1_1 mutants demonstrated significant differences in plant yield related traits like seed yield per plant, seed number per plant and siliques per plant compared to the wildtype plants (Fig. 4). ap1_1 mutant plants had an average seed yield per plant of $1.75 \pm 1.1 \mathrm{~g}$ compared to $0.84 \pm$ $0.7 \mathrm{~g}$ for the wildtype plants.

We observed that ap1_2 and ap1_3 mutant plants did not display any variation in floral bud development compared to their respective wildtype genotypes. Nevertheless, ap1_2 mutant plants exhibited significant differences in plant and branch height, while ap1_3 mutant plants had significantly different branch height and branch numbers (Fig. 4). We did not observe any significant difference in yield related traits for $a p 1 \_2$ and ap1_3 mutant plants. 


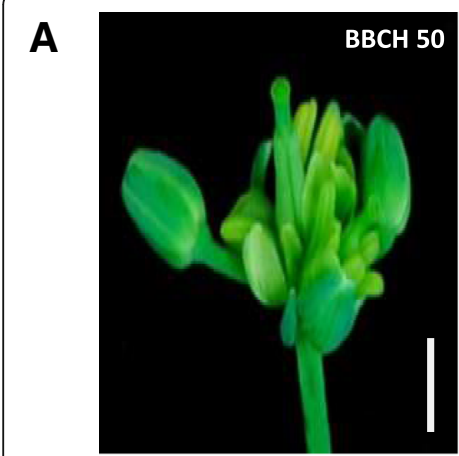

B
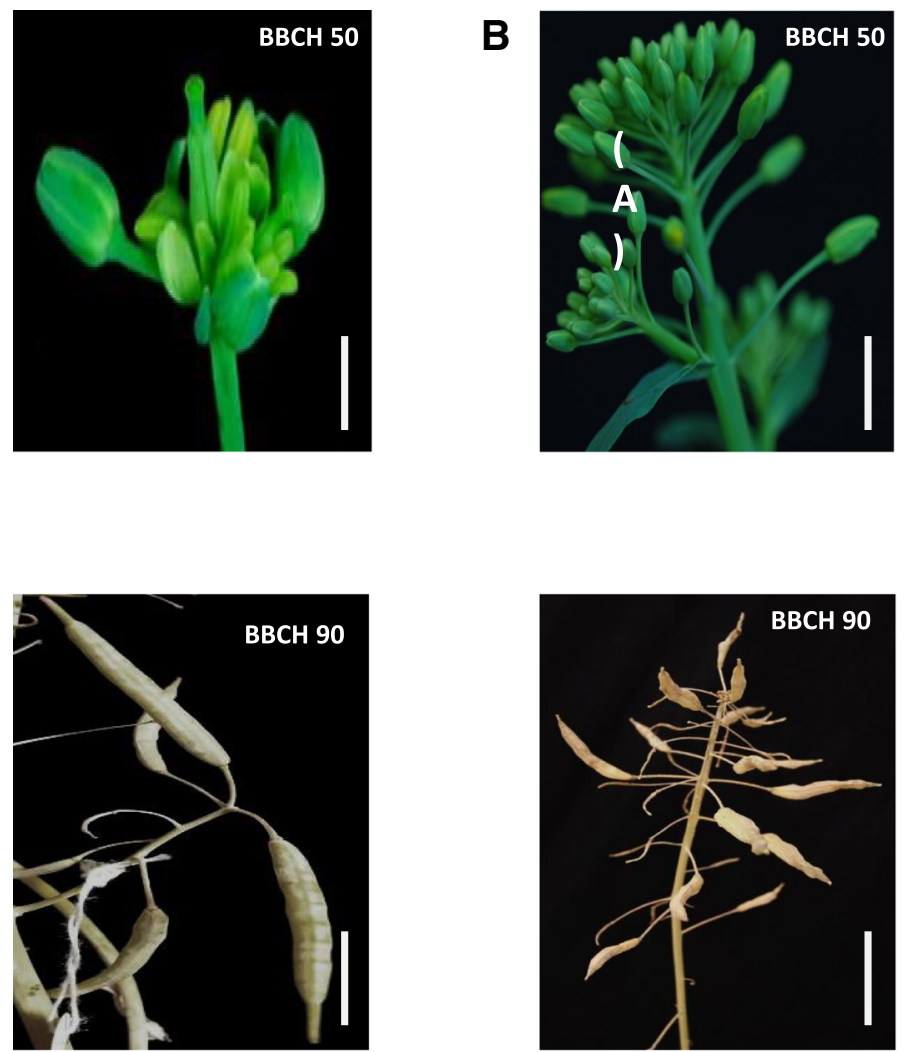

C

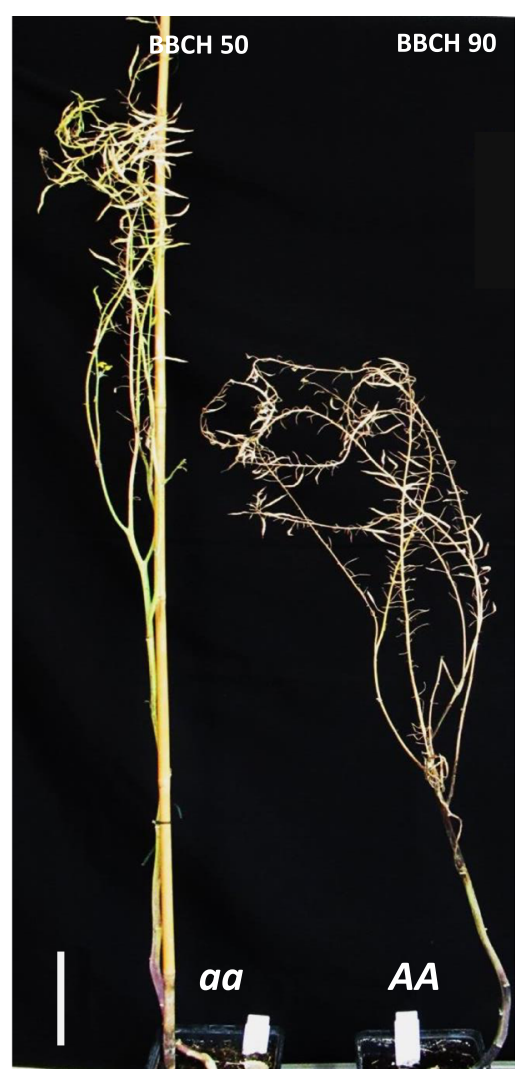

Fig. 3 Morphological features of the ap1_1 stop codon mutant family. Floral buds and silique development in ap 1_1 mutant plants (aa) are shown on the left (a; scale bar: $1 \mathrm{~cm})$; Floral buds and silique development in homozygous wildtype plants $(A A)$ in the center $(\mathbf{b}$; scale bar: $1 \mathrm{~cm}$ for $\mathrm{BBCH} 50$ and $10 \mathrm{~cm}$ for $\mathrm{BBCH} 90)$ and whole plant pictures with both genotypes on the right (c; scale bar: $10 \mathrm{~cm})$. Plants were grown in the greenhouse at constant temperature $\left(22^{\circ} \mathrm{C}\right)$, under long day conditions ( $16 \mathrm{~h} \mathrm{light)}$ after vernalization $\left(4{ }^{\circ} \mathrm{C}\right.$, $\left.16 \mathrm{~h} \mathrm{light,} 8 \mathrm{weeks}\right)$

\section{A stop codon mutation in Bna.AP1.A02 alters the} expression of Bna.TFL1 and Bna.FUL in the SAM

We expected that a stop codon mutation in Bna.AP1.A02 paralog impacts the expression of its downstream target genes. Therefore, we measured the expression of putative downstream target genes in the SAM of Bna.AP1.A02 stop codon mutant families. We took SAM samples from the greenhouse-grown plants between zeitgeber time 8 and 9. Based on the knowledge from Arabidopsis, we selected Bna.TFL1, Bna.FUL, Bna.LFY and Bna.SEP4 as putative downstream targets of Bna.AP1. We observed 2-fold higher joined expression of all Bna.TFL1 paralogs in ap1_1 mutants compared to wildtype plants (Fig. 5). When we measured the expression of Bna.TFL1 paralogs separately, we observed a similar expression pattern for three out of four paralogs in ap1_1 mutants (Fig. 5). Due to high sequence similarity, we could not design paralog-specific primers for Bna.TFL.Cnn. We did not observe any significant difference in the expression of Bna.TFL1 paralogs in ap1_2 and ap1_3 mutant plants. To further study the interaction between Bna.AP1 and Bna.TFL1, we reasoned that the expression of Bna.AP1 also decreases in Bna.TFL1 mutants, as it is the case for
Arabidopsis. For this purpose, we investigated the combined as well as paralog-specific (Bna.AP1.A02) expression of BnAP1 in a Bna.TFL1.A10 missense mutant family identified in a previous study [35]. We observed that after two generations of backcrossing, the plants carrying a missense mutation in Bna.TFL1.A10 showed lower combined and paralog-specific (Bna.AP1.A02) expression compared to the wildtype plants (Additional file 4: Figure S1).

Besides Bna.TFL1, we detected significantly lower expression of Bna.FUL in ap1_1 mutants compared to wildtype, but we did not observe any significant difference in the expression of Bna.SEP4 and Bna.LFY between the mutants and controls. Moreover, we also did not detect any significant difference in the expression of any of the putative downstream target genes in ap1_2 and ap1_3 mutant plants (Fig. 5). We observed that there was no significant difference in the Bna.AP1 combined and paralog-specific (Bna.AP1.A02) expression between the mutant and wildtype genotypes for ap1_1 and ap1_2 mutant families (Additional file 5: Figure S2). Nevertheless, there was a significant difference in combined and paralog-specific (Bna.AP1.A02) expression 


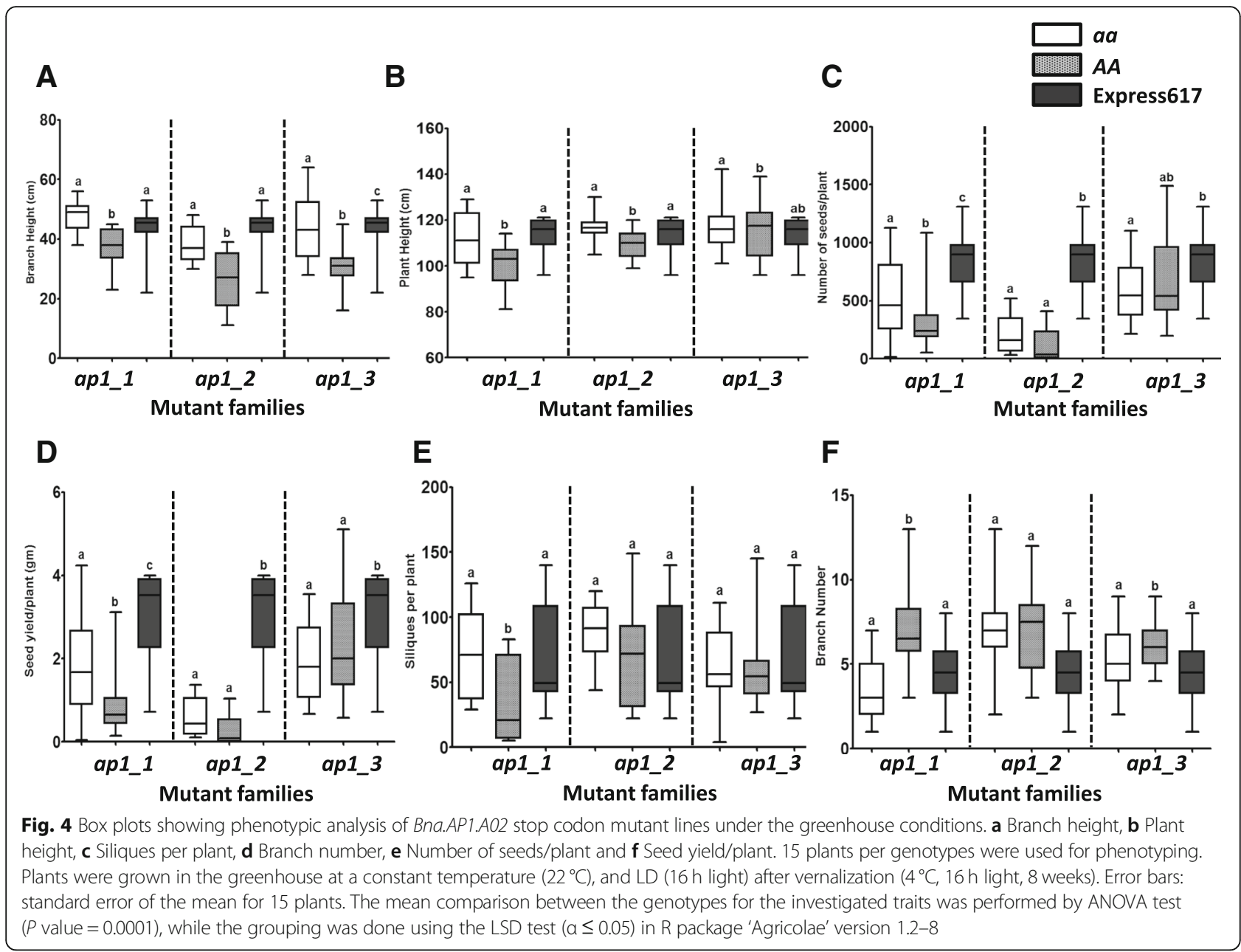

between the mutant and wildtype genotypes for the ap1_3 mutant family.

\section{Discussion}

The aim of this study was to characterize the role of AP1 orthologs in rapeseed. We hypothesized that the function of AP1 is conserved between rapeseed and Arabidopsis. The main findings of this study can be summarized as follows: (1) a stop codon mutation in Bna.AP1.A02 strongly affects plant architecture and seed yield-related traits, (2) the same mutation alters the plant architecture and increases the number of seeds per plant. (3) Moreover, the stop codon mutation in the $\mathrm{K}$ domain of Bna.AP1.A02 leads to altered expression of the putative downstream target genes Bna.TFL and Bna.FUL. Combining all these data, we found compelling evidence that the stop codon mutation in the $\mathrm{K}$ domain of Bna.AP1.A02 leads to architectural changes in rapeseed, with an impact on seed yield components.

TILLING offers a non-transgenic, rapid and cost-efficient method for detection of point mutations, which can be used to target each homologue of a multigene family independently. After phenotypic evaluation of TILLING mutants, favorable alleles can be combined into a single line by crossing single mutant parents. The frequency of EMS mutations depends on several factors like plant species, target tissue, the developmental stage of the target tissue, mutagen and also the concentration of mutagen [28]. Based on the previous studies, mutation frequencies vary in Brassicaceae family. For example, it was reported to be $1 / 345 \mathrm{~kb}$ in Arabidopsis [36], which was lower than mutation frequency in rapeseed $(1 / 41.5 \mathrm{~kb}$, [37]. Moreover, a higher mutation frequency of $1 / 56 \mathrm{~kb}$ was observed in $B$. rapa [38] compared to B. oleracea; (1/447 kb, [39]). Apart from Brassicaceae family, Chen et al. [40, 41] reported $1 / 47 \mathrm{~kb}$ mutation frequency in hexaploid wheat, while Till et al. [42] reported $1 / 300 \mathrm{~kb}$ mutation frequency in rice. Based on these studies, it was evident that the mutation frequency in diploid species is expected to be lower than in polyploid species. In our study, we calculated the mutation frequencies of $1 / 17.4$ $\mathrm{kb}$ and $1 / 26 \mathrm{~kb}$ for Bna.AP1.A02 and Bna.AP1.C02, respectively. Mutation frequency observed in this study is 


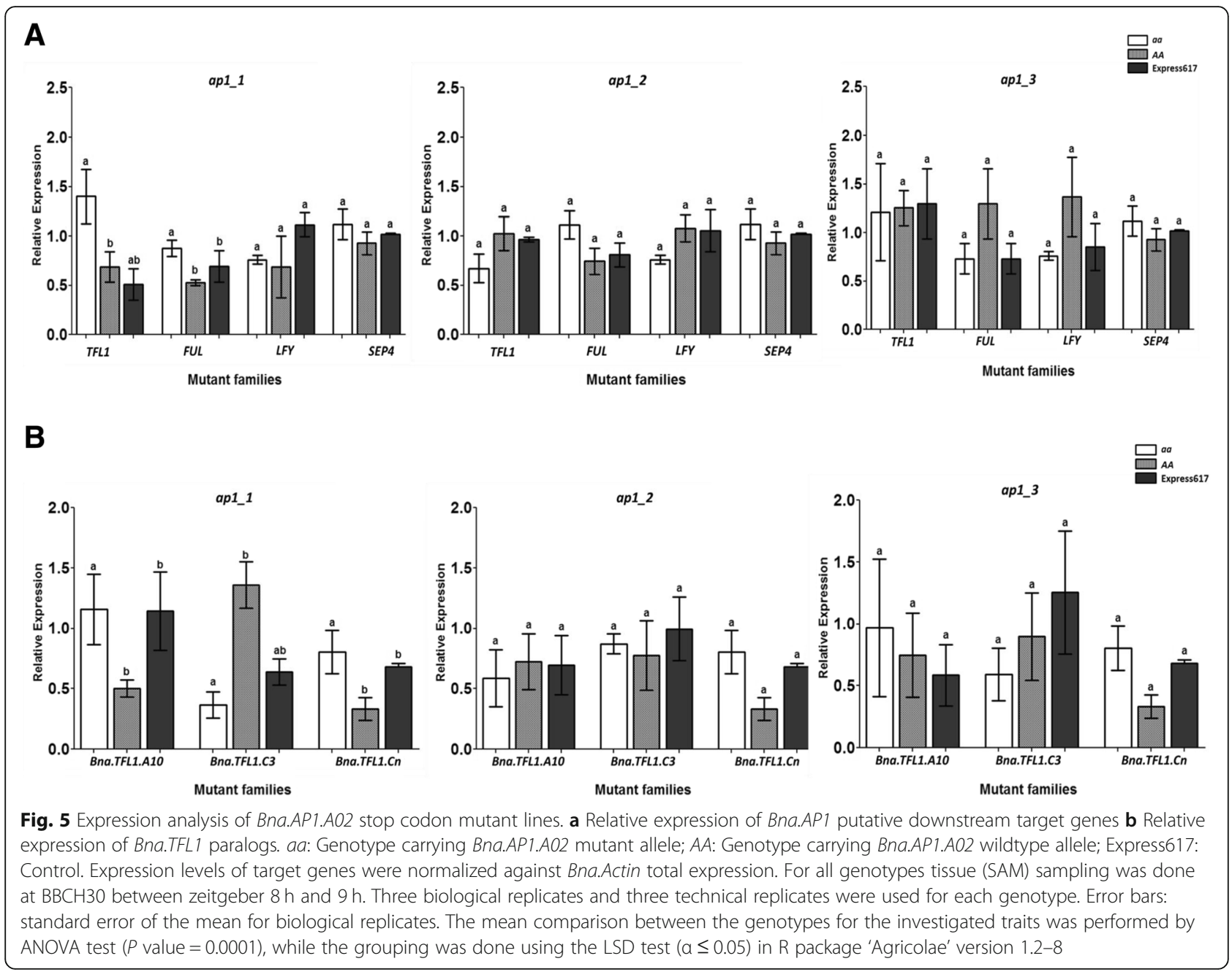

similar to mutation frequencies reported by Harloff et al. [28] for sinapine biosynthesis genes; (1/12 kb to $1 / 22 \mathrm{~kb})$ but higher than reported mutation frequencies by Guo et al. [35] for flowering time genes Bna.TFL1 and Bna.FT; $(1 / 24 \mathrm{~kb}$ to $1 / 72 \mathrm{~kb})$, using the same EMS population.

\section{Bna.AP1 has functions beyond conferring meristem identity in rapeseed}

In the current study, we aimed to evaluate the function of an AP1 homolog in rapeseed. In Arabidopsis, AP1 confers meristem identity with an essential role in sepal and petal development [23]. Moreover, an AP1 mutation in Arabidopsis resulted in delayed flowering [43]. Considering the close phylogenetic relationships between Arabidopsis and rapeseed, we expected that rapeseed plants carrying missense or nonsense mutations in AP1 paralogs show the same phenotype as Arabidopsis AP1 mutants. Unlike Arabidopsis, we did not observe any significant difference in flowering time between mutant and wildtype plants, which indicates that Bna.AP1.A02 does not affect flowering time in rapeseed. However, in a previous study, Schiessl et al. [34] found SNPs in Bna.AP1 between early and late flowering winter rapeseed lines, suggesting a potential role of Bna.AP1 in controlling flowering time in rapeseed. One possible explanation for the identical flowering time phenotype of mutant and wildtype plants can be the presence of five non-mutated Bna.AP1 paralogs in ap1_1 mutant plants.

We also evaluated floral and plant architecture in ap1_1 mutant and wildtype plants. We observed the development of floral buds in the axil of transformed sepals in ap1_1 mutant plants, which confirmed the conserved role of $A P 1$ as meristem identity gene in rapeseed. However, we did not observe this phenotype in all flowers of the mutant plants. The presence of flowers with normally developed sepals and petals on ap1_1 mutant plants can be due to the compensation by the other non-mutated paralogs of Bna.AP1. A similar phenomenon has been reported for the INDEHISCENT (Bna.IND) gene, where a mutation in a single paralog of Bna.IND gene does not affect the shatter resistance in 
rapeseed due to the presence of other functional copies of the gene [44]. However, the authors observed a significant increase in shatter resistance, when both paralogs of Bna.IND were mutated. Therefore, inducing mutation in all functional copies of Bna.AP1 might result in a stronger ap1_1 phenotype.

In polyploid plants like rapeseed, duplicated genes may undergo varying fate like sub-/neo-functionalization [45] or gene loss [46]. We wanted to analyze whether Bna.AP1.A02 paralog has other functions beyond conferring floral meristem identity in rapeseed. For this purpose, we analyzed the effect of the mutation on plant architecture, yield-related traits as well as the transcriptional activities of its putative downstream target genes. We observed that apart from floral architecture, a stop codon mutation in the $\mathrm{K}$ domain of Bna.AP1.A02 also altered plant architecture-related traits like branch height, plant height and branch number, which is in accordance with studies in other crop plants. In rice (Oryza sativa L), plant architecture was altered after overexpression of OsMADS15, an ortholog of Arabidopsis AP1 [18]. Burko et al. [17] showed the role of tomato AP1/FUL in tomato leaf development. Besides plant architecture, in previous studies, it has been demonstrated that meristem identity genes also affect seed yield-related traits. For instance, in a previous study, it was reported that meristem identity gene, APETALA2 (AP2) controls seed yield and seed mass in Arabidopsis [47]. Furthermore, a homolog of meristem identity gene FUL also showed indication of neo-functionalization in rapeseed [33]. Nevertheless, there is no previous report on the role of AP1 in controlling seed yield related traits in Arabidopsis. Hence, the results from the current study, indicating the involvement of Bna.AP1.A02 in controlling plant architecture and seed yield related traits hints towards neo-functionalization of the meristem identity gene $A P 1$ in rapeseed.

\section{Bna.AP1.A02 is an upstream regulator of Bna.TFL1 and $B n a . F U L$ in rapeseed meristem}

Because Bna.AP1.A02 stop codon mutation had a substantial effect on plant architecture and yield-related traits; we expected an altered expression of genes which are transcriptionally regulated by Bna.AP1. The increased expression of Bna.TFL1 paralogs in the ap1-1 mutant in rapeseed is in accordance with the relationship between TFL1 and AP1 in Arabidopsis, where constitutive expression of $A P 1$ downregulated the activity of TFL1 [48]. A higher expression of Bna.TFL1 might be the reason for the increased number of branches, and plant height in ap1_1 mutant plants compared to wildtype plants since previous studies in Arabidopsis and other species have shown that the overexpression of
TFL1 and its homologs causes highly branched inflorescences and thus, altered plant architecture [49-52]. However, the decreased expression of Bna.AP1 in Bna.TFL1 missense mutant plants hints towards a different transcriptional regulation between Bna.AP1 and $B n a . T F L 1$ in rapeseed. Moreover, the lower expression of Bna.FUL in the ap1_1 mutant in the current study was also in contrast with the expression profile in Arabidopsis, where $F U L$ was ectopically expressed in the floral meristem of an AP1 mutant [53]. Nevertheless, in another study, it was observed that overexpression of Jatropha AP1 ortholog (JcAP1) in Arabidopsis caused higher expression of FUL [24]. Hence, the data from current and previous studies suggest that despite of functional conservation, meristem identity genes might display varying transcriptional regulation in other crops compared to Arabidopsis. Based on transcriptional data of Bna.AP1, Bna.FUL and Bna.TFL1 from the current study, we propose a model of gene interaction: (1) Bna.AP1.A02 suppresses the expression of three Bna.TFL1 paralogs (2) Bna.TFL1.A10 induces or maintains the expression of Bna.AP1.A02 and (3) Bna.AP1.A02 is necessary for maintaining the transcript level of Bna.FUL. We propose that analyzing the expression of Bna.TFL1, Bna.FUL and Bna.AP1 in CRISPR-Cas mutants of meristem identity genes can depict the transcriptional regulation between these genes in a much clearer way because CRISPR-Cas technology can generate site-specific mutants without any background mutations. The expression and phenotypic data of Bna.AP1.A02 mutant plants from the current study provide strong evidence for the involvement of this homolog of AP1 in controlling processes beyond its function as a meristem identity gene in rapeseed. There is evidence of nonsense mediated decay in different crop species like rapeseed [54], wheat [55] and barley [56]. Nevertheless, we did not observe any evidence of nonsense mediated decay in the current study.

Based on phenotypic and expression data, ap1_1 showed a stronger effect on floral architecture, plant architecture and yield-related traits compared to ap1_2 and ap1_3. This was in accordance with our expectations because ap1_1 carried a mutation in exon four, which results in the shortest protein among all mutants, lacking a K- and $\mathrm{COOH}$-domain. The other two mutants, ap1_2 and ap1_3 carried mutations in exon 7 and exon 8 , respectively. Hence, proteins encoded by these mutants are only lacking the $\mathrm{COOH}$ domain. There is a considerable amount of evidence in Arabidopsis, emphasizing the significant role of different AP1 domains in the protein function and its interaction with other proteins for the functional specificity. In a previous study [57], chimeric constructs between AtAP1 and CAULIFLOWER (AtCAL) were used to demonstrate that $\mathrm{K}$ domain and $\mathrm{COOH}$ domain of $A P 1$ are important for 
conferring floral meristem identity. In another study [58], a $9 \mathrm{bp}$ insertion was found in the exon 4 of $B o A P 1-B$ gene in B. oleracea ssp. botrytis (domesticated cauliflower) and in B. oleracea ssp. oleracea (wild cabbage), that lead to a premature stop codon. As a result of these mutations, in both cases, the BoAP1- $B$ gene was coding for a truncated protein lacking a part of the $\mathrm{K}$ domain and the entire $\mathrm{COOH}$ domain, leading to the cauliflower phenotype. Our phylogenetic analysis of AP1 protein sequences from different Brassicaceae species revealed that Bna.AP1.A02 groups strongly with Bna.AP1.C02 and also a copy from B. oleracea (Bog062650) (Additional file 6: Figure S3). This provides preliminary evidence about the similar role of these copies in their respective species.

\section{Conclusions}

In the current study, we found that a stop codon mutation in the $\mathrm{K}$ domain of Bna.AP1.A02 leads to altered flower morphology, plant architecture and higher yield compared to the wildtype plants. However, further yield trials in multiple locations and years are needed to investigate the role of Bna.AP1.A02 in controlling seed yield in rapeseed. Moreover, reduction of the mutation load is required, which can be achieved by backcrossing with an elite line. Besides, marker assisted background selection [59] can be a time-saving approach, where $\mathrm{BC}_{1}$ plants are genotyped with numerous markers to select plants with a high share of the recipient genome. This can be achieved with whole genome sequencing data, rapeseed SNP arrays [60] or by AFLP markers (Amplified Fragment Length Polymorphism [61]). Recently, Braatz et al. [62] demonstrated the potential of CRISPR-Cas technology in creating targeted genetic modification in rapeseed. In this way, all paralogs of any gene of interest in rapeseed can be mutagenized at the same time to study the function of the gene. If the effect of the ap1_1 mutation on yield is proven under field conditions, new ap1_1 alleles can be selected from the rapeseed gene pool. These alleles and the mutant alleles we created can be introduced into rapeseed breeding programs by conventional backcrossing with elite rapeseed germplasms to produce agronomically superior genotypes.

\section{Additional files}

Additional file 1: Table S1. Primers used in this study for screening mutations in Express617 EMS population and for expression analysis by RT-qPCR. (DOCX $19 \mathrm{~kb})$

Additional file 2: Table S2. Details of EMS mutations in Bna.AP1.A02 and Bna.AP1.C02 paralogs detected by TILLING of Express 617. (DOCX $13 \mathrm{~kb}$ )

Additional file 3: Table S3. Nucleotide position and amino acid changes in different splice site, non-sense and UTR mutants from Bna.AP1.A02 and Bna.AP1.C02 paralogs. The phenotyping was performed with plants from the M4 generation. (DOCX $14 \mathrm{~kb}$ )
Additional file 4: Figure S1. Relative expression of Bna.AP1 in $\mathrm{BC}_{2} \mathrm{~F}_{3}$ lines homozygous for Bna.TFL1.A10 missense mutation (Guo et al., 2014). (A) Combined expression of Bna.AP1 (B) Paralog-specific (Bna.AP1.A02). aa-M $\mathrm{M}_{4}$ : Genotype carrying Bna.TFL1.A10 missense mutation ( $\mathrm{M}_{4}$ generation); aa-BC2 $F_{3}$ : Genotype having homozygous Bna.TFL1.A10 missense mutation in a $\mathrm{BC}_{2} \mathrm{~F}_{3}$ generation; $A A$ : Genotype carrying Bna.TFL1.A10 wildtype allele in $\mathrm{BC}_{2} \mathrm{~F}_{3}$ generation; Express617: Control. Expression levels of target genes were normalized against Bna.Actin total expression. For all genotypes tissue (SAM) sampling was done between zeitgeber $8 \mathrm{~h}$ and 9 $\mathrm{h}$. Three biological replicates and three technical replicates were used for each genotype. Error bars: standard error of the mean for biological replicates. The mean comparison between the genotypes for the investigated traits was performed by ANOVA test $(P$ value $=0.0001$ ), while the grouping was done using the LSD test $(a \leq 0.05)$ in R package 'Agricolae' version 1.2-8. (PPTX $522 \mathrm{~kb}$ )

Additional file 5: Figure S2. Relative paralog-specific (Bna.AP1.A 02) (Fig. A) and combined expression of Bna.AP1 (Fig. B) in Bna.AP1.A02 stop codon mutant lines. aa: Genotype carrying Bna.AP1.A02 mutant allele; AA: Genotype carrying Bna.AP1.A02 wildtype allele; Express617: Control. For all genotypes tissue (SAM) sampling was done between zeitgeber $8 \mathrm{~h}$ and 9 $\mathrm{h}$ Three biological replicates and three technical replicates were used for each genotype. Error bars: standard error of the mean for biological replicates. The mean comparison between the genotypes for the investigated traits was performed by ANOVA test ( $\mathrm{P}$ value $=0.0001$ ), while the grouping was done using the LSD test $(a \leq 0.05)$ in R package 'Agricolae' version 1.2-8. (PPTX 428 kb)

Additional file 6: Figure S3. Phylogenetic tree of AP1 protein sequences from different Brassicaceae species. The tree was constructed using the Neighbour-Joining method. The default bootstrap value was set to 100 . The numbers on branches represent bootstrap values in percentage. (PPTX $245 \mathrm{~kb}$ )

\section{Abbreviations}

2D: Two-dimensional; 8x: Eight-fold; AFLP: Amplified fragment length polymorphism; AG: AGAMOUS; AGL: AGAMOUS LIKE; ANOVA: Analysis of variance; AP1: APETALA1; AP2: APETALA2; AP3: APETALA3; CAL: CAULIFLOWER; CO: CONSTANS; DH: Doubled haploid; EST: Expressed sequence tags; FT: FLOWERING LOCUS T; FUL: FRUITFULL; IND: INDEHISCENT; IPA: Ideal plant architecture; LFY: LEAFY; PAGE: Polyacrylamide gel electrophoresis; PI: PISTILLATA; QTL: Quantitative trait loci; RT-qPCR: Real-time quantitative PCR: SAM: Shoot apical meristem; SEP: SEPALLATA; SEP3: SEPALLATA3:

TFL1: TERMINAL FLOWER 1; TILLING: Targeting induced local lesions in genomes

\section{Acknowledgements}

We thank Monika Bruisch for technical assistance. We are also thankful to the Institute of Clinical Molecular Biology in Kiel for Sanger sequencing and the breeding company Norddeutsche Pflanzenzucht Hans-Georg Lembke for supplying seeds from the EMS mutant population.

\section{Funding}

This study has been funded in the frame of the DFG priority program 1530 (Flowering time control: from natural variation to crop improvement, grant number JU205/19-1). The current study has been discussed with other scientists in the field of plant breeding during different conferences and workshops organized by the DFG and their suggestions and recommendation have been considered for the improvement of the current manuscript. We acknowledge the financial support by State of SchleswigHolstein, Germany within the funding program "Open Access Publikationsfonds".

Availability of data and materials

The datasets used and/or analyzed during the current study are available from the corresponding author on reasonable request.

\section{Authors' contributions}

SS planned, performed, and analyzed the experiments and drafted the article; NLK identified the TILLING mutants; NE and CJ contributed to the overall design of the study, supervised the experiments, and revised the article; all authors read and approved the final article. 


\section{Ethics approval and consent to participate}

All the plant material (seeds) used in the current study were produced directly in the Plant Breeding Institute or at the breeding company Norddeutsche Pflanzenzucht Hans-Georg Lembke.

\section{Consent for publication}

Not applicable.

\section{Competing interests}

The authors declare that they have no competing interests.

\section{Publisher's Note}

Springer Nature remains neutral with regard to jurisdictional claims in published maps and institutional affiliations.

\section{Received: 28 November 2018 Accepted: 17 December 2018} Published online: 29 December 2018

\section{References}

1. Cai G, Yang Q, Chen H, Yang Q, Zhang C, Fan C, Zhou Y. Genetic dissection of plant architecture and yield-related traits in Brassica napus. Sci Rep. 2016;6:21625

2. Blümel $M$, Dally $N$, Jung C. Flowering time regulation in crops - what did we learn from Arabidopsis? Curr Opin Biotechnol. 2015:32:121-9.

3. Javed N, Geng J, Tahir M, McVetty P, Li G, Duncan RW. Identification of QTL influencing seed oil content, fatty acid profile and days to flowering in Brassica napus L. Euphytica. 2016;207(1):191-211.

4. Luo Y, Luo C, Du D, Fu Z, Yao Y, Xu C. Quantitative trait analysis of flowering time in spring rapeseed (B. napus L.). Euphytica. 2014;200:321-35.

5. Liu H, Du D, Guo S, Xiao L, Zhao Z, Zhao Z, Xing X, Tang G, Xu L, Fu $Z$, et al. QTL analysis and the development of closely linked markers for days to flowering in spring oilseed rape (Brassica napus L.). Mol Breed. 2016;36(5):1-14

6. Raman H, Raman R, Eckermann P, Coombes N, Manoli S, Zou X. Genetic and physical mapping of flowering time loci in canola (Brassica napus L.). Theor Appl Genet. 2013;126:119-32.

7. Jiao Y, Wang Y, Xue D, Wang J, Yan M, Liu G. Regulation of OsSPL14 by OsmiR156 defines ideal plant architecture in rice. Nat Genet. 2010;42:541-4

8. Tian F, Bradbury PJ, Brown PJ, Hung H, Sun Q, Flint-Garcia S, Rocheford TR, McMullen MD, Holland JB, Buckler ES. Genome-wide association study of leaf architecture in the maize nested association mapping population. Nat Genet. 2011:43:159.

9. Ku L, Zhao W, Zhang J, Wu L, Wang C, Wang P, Zhang W, Chen Y. Quantitative trait loci mapping of leaf angle and leaf orientation value in maize (Zea mays L.). Theor Appl Genet. 2010;121(5):951-9.

10. Qiu D, Morgan C, Shi J, Long Y, Liu J, Li R, Zhuang X, Wang Y, Tan X, Dietrich $E$, et al. A comparative linkage map of oilseed rape and its use for QTL analysis of seed oil and erucic acid content. Theor Appl Genet. 2006; 114(1):67-80.

11. Chen B, Xu K, Li J, Li F, Qiao J, Li H, Gao G, Yan G, Wu X. Evaluation of yield and agronomic traits and their genetic variation in 488 global collections of Brassica napus L. Genet Resour Crop Evol. 2014;61(5):979-99.

12. Shen $Y$, Xiang $Y, X u$ E, Ge X, Li Z. Major co-localized QTL for plant height, branch initiation height, stem diameter, and flowering time in an alien introgression derived Brassica napus DH population. Front Plant Sci. 2018;9:390.

13. Shen Y, Yang Y, Xu E, Ge X, Xiang Y, Li Z. Novel and major QTL for branch angle detected by using $\mathrm{DH}$ population from an exotic introgression in rapeseed (Brassica napus L.). Theor Appl Genet. 2018;131(1):67-78.

14. Schiessl S, Iniguez-Luy F, Qian W, Snowdon RJ. Diverse regulatory factors associate with flowering time and yield responses in winter-type Brassica napus. BMC Genomics. 2015;16(1):1-20.

15. Li H, Zhang L, Hu J, Zhang F, Chen B, Xu K, Gao G, Li H, Zhang T, Li Z, et al. Genome-wide association mapping reveals the genetic control underlying branch angle in rapeseed (Brassica napus L.). Front Plant Sci. 2017:8:1054

16. Zheng M, Peng C, Liu H, Tang M, Yang H, Li X, Liu J, Sun X, Wang X, Xu J, et al. Genome-wide association study reveals candidate genes for control of plant height, branch initiation height and branch number in rapeseed (Brassica napus L.). Front Plant Sci. 2017;8:1246.
17. Burko Y, Shleizer-Burko S, Yanai O, Shwartz I, Zelnik ID, Jacob-Hirsch J, Kela I, Eshed-Williams L, Ori N. A role for APETALA1/FRUITFULL transcription factors in tomato leaf development. Plant Cell. 2013;25(6):2070-83.

18. Lu S-J, Wei H, Wang Y, Wang H-M, Yang R-F, Zhang X-B, Tu J-M. Overexpression of a transcription factor OSMADS15 modifies plant architecture and flowering time in Rice (Oryza sativa L.). Plant Mol Biol Report. 2012;30(6):1461-9.

19. Rao NN, Prasad K, Kumar PR, Vijayraghavan U. Distinct regulatory role for $R F L$, the rice $L F Y$ homolog, in determining flowering time and plant architecture. Proc Natl Acad Sci. 2008;105(9):3646-51.

20. Hugouvieux $V$, Silva CS, Jourdain A, et al. Tetramerization of MADS family transcription factors SEPALLATA3 and AGAMOUS is required for floral meristem determinacy in Arabidopsis. Nucleic Acids Res. 2018;46(10):4966-77.

21. Liu Z, Mara C. Regulatory mechanisms for floral homeotic gene expression. Semin Cell Dev Biol. 2010;21(1):80-86.

22. Alejandra Mandel M, Gustafson-Brown C, Savidge B, Yanofsky MF. Molecular characterization of the Arabidopsis floral homeotic gene APETALA1. Nature. 1992;360:273.

23. Irish VF, Sussex IM. Function of the apetala-1 gene during Arabidopsis floral development. Plant Cell. 1990;2(8):741-53.

24. Tang M, Tao Y-B, Xu Z-F. Ectopic expression of Jatropha curcas APETALA1 (JCAP1) caused early flowering in Arabidopsis, but not in Jatropha. PeerJ. 2016:4:e1969.

25. Sun L-M, Zhang J-Z, Mei L, Hu C-G. Molecular cloning, promoter analysis and functional characterization of APETALA 1-like gene from precocious trifoliate orange (Poncirus trifoliata L. Raf.). Sci Hortic. 2014;178:95-105.

26. Berbel A, Navarro C, Ferrándiz C, Cañas LA, Madueño F, Beltrán JP. Analysis of PEAM4, the pea AP1 functional homologue, supports a model for AP1 like genes controlling both floral meristem and floral organ identity in different plant species. Plant J. 2001;25(4):441-51.

27. Chen M-K, Lin I-C, Yang C-H. Functional analysis of three lily (Lilium longiflorum) APETALA1-like MADS box genes in regulating floral transition and formation. Plant Cell Physiol. 2008:49(5):704-17.

28. Harloff H-J, Lemcke S, Mittasch J, Frolov A, Wu JG, Dreyer F, Leckband G, Jung C. A mutation screening platform for rapeseed (Brassica napus L.) and the detection of sinapine biosynthesis mutants. Theor Appl Genet. 2012;124(5):957-69.

29. Chalhoub B, Denoeud F, Liu S, Parkin IAP, Tang H, Wang X, Chiquet J, Belcram H, Tong C, Samans B, et al. Early allopolyploid evolution in the post-Neolithic Brassica napus oilseed genome. Science. 2014;345(6199):950-3.

30. Zerr T, Henikoff S. Automated band mapping in electrophoretic gel images using background information. Nucleic Acids Res. 2005;33(9):2806-12.

31. Meier U. Growth stages of mono-and dicotyledonous plants. BBCH Monograph. In: Federal Biological Research Centre for Agriculture and Forestry, Germany; 2001.

32. Livak KJ, Schmittgen TD. Analysis of relative gene expression data using realtime quantitative $P C R$ and the 2- $\Delta \Delta C T$ method. Methods. 2001;25(4):402-8

33. Shah S, Weinholdt C, Jedrusik N, Molina C, Zou J, Große I, Schiessl S, Jung C, Emrani N. Whole transcriptome analysis reveals genetic factors underlying flowering time regulation in rapeseed (Brassica napus L.). Plant. Cell and Environment. 2018:41:1935-47.

34. Schiessl S, Samans B, Huttel B, Reinhardt R, Snowdon R. Capturing sequence variation among flowering-time regulatory gene homologs in the allopolyploid crop species Brassica napus. Front Plant Sci. 2014;5:404.

35. Guo $Y$, Hans H, Christian J, Molina C. Mutations in single FT-and TFL 1paralogs of rapeseed (Brassica napus L.) and their impact on flowering time and yield components. Front Plant Sci. 2014;5:0282.

36. Lai K-S, Kaothien-Nakayama P, Iwano M, Takayama S. A TILLING resource for functional genomics in Arabidopsis thaliana accession C24. Genes and genetic systems. 2012;87(5):291-7.

37. Wang N, Wang Y, Tian F, King GJ, Zhang C, Long Y, Shi L, Meng J. A functional genomics resource for Brassica napus: development of an EMS mutagenized population and discovery of FAE1 point mutations by TILLING. New Phytol. 2008;180(4):751-65.

38. Stephenson P, Baker D, Girin T, Perez A, Amoah S, King GJ, Østergaard L. A rich TILLING resource for studying gene function in Brassica rapa. BMC Plant Biol. 2010;10(1):62

39. Himelblau E, Gilchrist EJ, Buono K, Bizzell C, Mentzer L, Vogelzang R, Osborn T, Amasino RM, Parkin IAP, Haughn GW. Forward and reverse genetics of rapid-cycling Brassica oleracea. Theor Appl Genet. 2009;118(5):953-61.

40. Chen L, Huang L, Min D, Phillips A, Wang S, Madgwick PJ, Parry MA, Hu Y-G. Development and characterization of a new TILLING population of common bread wheat (Triticum aestivum L.). PLoS One. 2012;7(7):e41570. 
41. Chen L, Song Y, Li S, Zhang L, Zou C, Yu D. The role of WRKY transcription factors in plant abiotic stresses. Biochim Biophys Acta Gene Regul Mech. 2012;1819(2):120-8.

42. Till BJ, Cooper J, Tai TH, Colowit P, Greene EA, Henikoff S, Comai L. Discovery of chemically induced mutations in rice by TILLING. BMC Plant Biol. 2007;7(1):19.

43. Piñeiro $M$, Coupland $G$. The control of flowering time and floral identity in Arabidopsis. Plant Physiol. 1998;117(1):1-8.

44. Braatz J, Harloff H-J, Emrani N, Elisha C, Heepe L, Gorb SN, Jung C. The effect of INDEHISCENT point mutations on silique shatter resistance in oilseed rape (Brassica napus). Theor Appl Genet. 2018;131(4):959-71.

45. Force A, Lynch M, Pickett FB, Amores A, Yan YL, Postlethwait J. Preservation of duplicate genes by complementary degenerative mutations. Genetics. 1999;151(4):1531-45.

46. Blanc G, Wolfe KH. Widespread paleopolyploidy in model plant species inferred from age distributions of duplicate genes. Plant Cell. 2004;16(7):1667-78

47. Jofuku KD, Omidyar PK, Gee Z, Okamuro JK. Control of seed mass and seed yield by the floral homeotic gene APETALA2. Proc Natl Acad Sci U S A. 2005;102(8):3117-22.

48. Liljegren SJ, Gustafson-Brown C, Pinyopich A, Ditta GS, Yanofsky MF. Interactions among APETALA1, LEAFY, and TERMINAL FLOWERT specify meristem fate. Plant Cell. 1999;11(6):1007-18.

49. Nakagawa M, Shimamoto K, Kyozuka J. Overexpression of RCN1 and RCN2, rice TERMINAL FLOWER 1/CENTRORADIALIS homologs, confers delay of phase transition and altered panicle morphology in rice. Plant J. 2002;29(6):743-50.

50. Jensen CS, Salchert K, Nielsen KK. A TERMINAL FLOWERT-like gene from perennial ryegrass involved in floral transition and axillary meristem identity. Plant Physiol. 2001;125(3):1517-28.

51. Carmona MJ, Calonje M, Martínez-Zapater JM. The FT/TFL1 gene family in grapevine. Plant Mol Biol. 2007;63(5):637-50

52. Danilevskaya ON, Meng X, Ananiev EV. Concerted modification of flowering time and inflorescence architecture by ectopic expression of TFL1-like genes in maize. Plant Physiol. 2010;153(1):238-51.

53. Ferrandiz C, Gu Q, Martienssen R, Yanofsky MF. Redundant regulation of meristem identity and plant architecture by FRUITFULL APETALA1 and CAULIFLOWER. Development. 2000;127(4):725-34.

54. Emrani N, Harloff H-J, Gudi O, Kopisch-Obuch F, Jung C. Reduction in sinapine content in rapeseed (Brassica napus $\mathrm{L}$.) by induced mutations in sinapine biosynthesis genes. Mol Breed. 2015;35(1):1-11.

55. Saito M, Nakamura T. Two point mutations identified in emmer wheat generate null Wx-A1 alleles. Theor Appl Genet. 2005;110(2):276-82.

56. Gadjieva R, Axelsson E, Olsson U, Vallon-Christersson J, Hansson M. Nonsensemediated mRNA decay in barley mutants allows the cloning of mutated genes by a microarray approach. Plant Physiol Biochem. 2004:42(7-8):681-5.

57. Alvarez-Buylla ER, García-Ponce B, Garay-Arroyo A. Unique and redundant functional domains of APETALA1 and CAULIFLOWER, two recently duplicated Arabidopsis thaliana floral MADS-box genes. J Exp Bot. 2006:57(12):3099-107.

58. Lowman AC, Purugganan MD. Duplication of the Brassica oleracea APETALA1 floral homeotic gene and the evolution of domesticated cauliflower. J Hered. 1999;90:514-20.

59. Jung C. Breeding with genetically modified plants. In: Kempken F, Berlin JC, editors. Genetic modification of plants: agriculture, horticulture and forestry. Heidelberg: Springer Berlin Heidelberg; 2010. p. 103-16.

60. Mason AS, Higgins EE, Snowdon RJ, Batley J, Stein A, Werner C, Parkin IAP. A user guide to the Brassica 60K Illumina Infinium ${ }^{\text {TM }}$ SNP genotyping array. Theor Appl Genet. 2017;130(4):621-33.

61. Schondelmaier J, Steinrücken G, Jung C. Integration of AFLP markers into a linkage map of sugar beet (Beta vulgaris L.). Plant Breed. 1996:115(4):231-7.

62. Braatz J, Harloff H-J, Mascher M, Stein N, Himmelbach A, Jung C. CRISPRCas9 Targeted Mutagenesis Leads to Simultaneous Modification of Different Homoeologous Gene Copies in Polyploid Oilseed Rape (Brassica napus). Plant Physiology. 2017;174(2):935-42.

\section{Ready to submit your research? Choose BMC and benefit from:}

- fast, convenient online submission

- thorough peer review by experienced researchers in your field

- rapid publication on acceptance

- support for research data, including large and complex data types

- gold Open Access which fosters wider collaboration and increased citations

- maximum visibility for your research: over $100 \mathrm{M}$ website views per year

At BMC, research is always in progress.

Learn more biomedcentral.com/submissions 